\title{
DESIGN AND FABRICATION OF A SHEARING MACHINE FOR GLASS FIBER SLEEVES USING STEPPER MOTOR AND PLC
}

\author{
Abhishek Gaonkar ${ }^{1}$, Sahil Kerkar ${ }^{2}$, Nandan Shirodkar ${ }^{3}$, Vikesh Hadfadkar ${ }^{4}$, Deu Sangelkar ${ }^{5}$ \\ ${ }^{1}$ B.E, Mechanical Dept., Padre Conceicao college of Engineering college, Goa, India \\ ${ }^{2}$ B.E, Mechanical Dept., Padre Conceicao college of Engineering college, Goa, India \\ ${ }^{3}$ B.E. Mechanical Dept., Padre Conceicao college of Engineering college, Goa, India \\ ${ }^{4}$ B.E, Mechanical Dept., Padre Conceicao college of Engineering college, Goa, India \\ ${ }^{5}$ B.E, Mechanical Dept., Padre Conceicao college of Engineering college, Goa, India
}

\begin{abstract}
This paper gives the reader an insight in to the work we went through to invent the concept for an automated fiber glass sleeve cutting machine. The challenge given to us by the Industry was to design and fabricate the shearing machine that can cut fiber glass sleeves in a given desired length automatically on a large scale. The length of the sleeve given to us is in range of 20mm$50 \mathrm{~mm}$. We set out to invent a simple but strong concept resulting in a machine with minimal complexity which will reduce the cost of production, time required to cut the sleeve and also improve the ease of maintenance. This paper is testament to how we achieved a supposedly complex automation using simple mechanical automation. To support our concept we also set out to fabricate a proposed machine to prove this concept will work.
\end{abstract}

Keywords: Shearing, Plc, Fiber glass sleeves, Ladder programming, Hmi

\section{INTRODUCTION}

Shearing refers more specifically to a mechanical process which cuts the material without formation of chips using cutting blade. [4]

In the industry, workers had to select glass fiber sleeves, measure the appropriate length and then cut it using a pair of scissors. The process was very tedious and time consuming. The motive behind our project is to Provide a fully automated machine to increase the output and reduce the operator fatigue. Our machine is a combination of electronics, mechanical and pneumatics. The controller system (PLC) and stepper motor will be used to control the feed and the cutting action with the help of air cylinder. A desired length of the sleeve to be cut Specified by the Industry is between $20 \mathrm{~mm}$ to $50 \mathrm{~mm}$.

\section{SLEEVE SPECIFICATION}

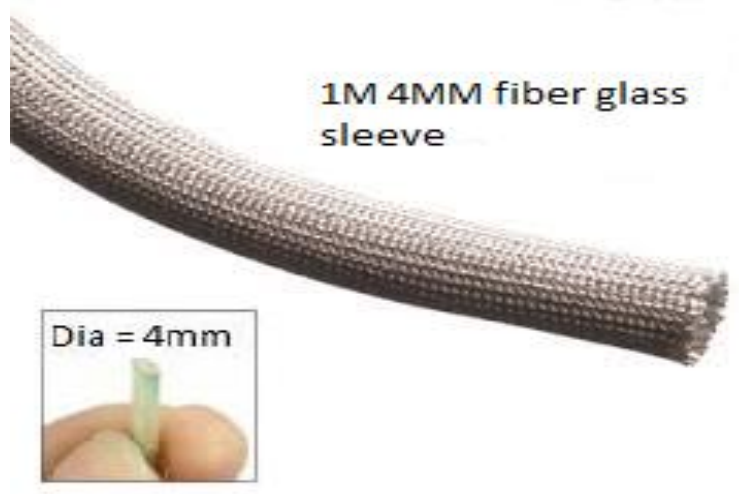

Fig-1: Fiber glass sleeve
The above fig. shows the high temp resistant fiber glass sleeve of length 1 meter and cross sectional diameter of 4 millimetres. Dimensions which are mentioned here were provided to us by the industry.

Length of the single sleeve $=1$ meter.

Length of the single sleeve (to be cut) $=20 \mathrm{~mm}-50 \mathrm{~mm}$.

Diameter of the single sleeve $=4 \mathrm{~mm}$.

Sleeve material $=$ Glass Fiber.

Grade of the material $=\mathrm{E}-$ Glass Fiber.

\section{IDEOLOGY}

\subsection{Inspiration}

The main inspiration for designing this machine was obtained while observing the manual cutting of sleeves through using scissor. So conclusion was we need an automated mechanism where bundle of Sleeve (10-15nos.) can cut at a time which makes process faster. 


\section{VISUALIZATION OF IMPORTANT COMPONENT}

\subsection{PLC (Programmable Logic Controller) [6]}

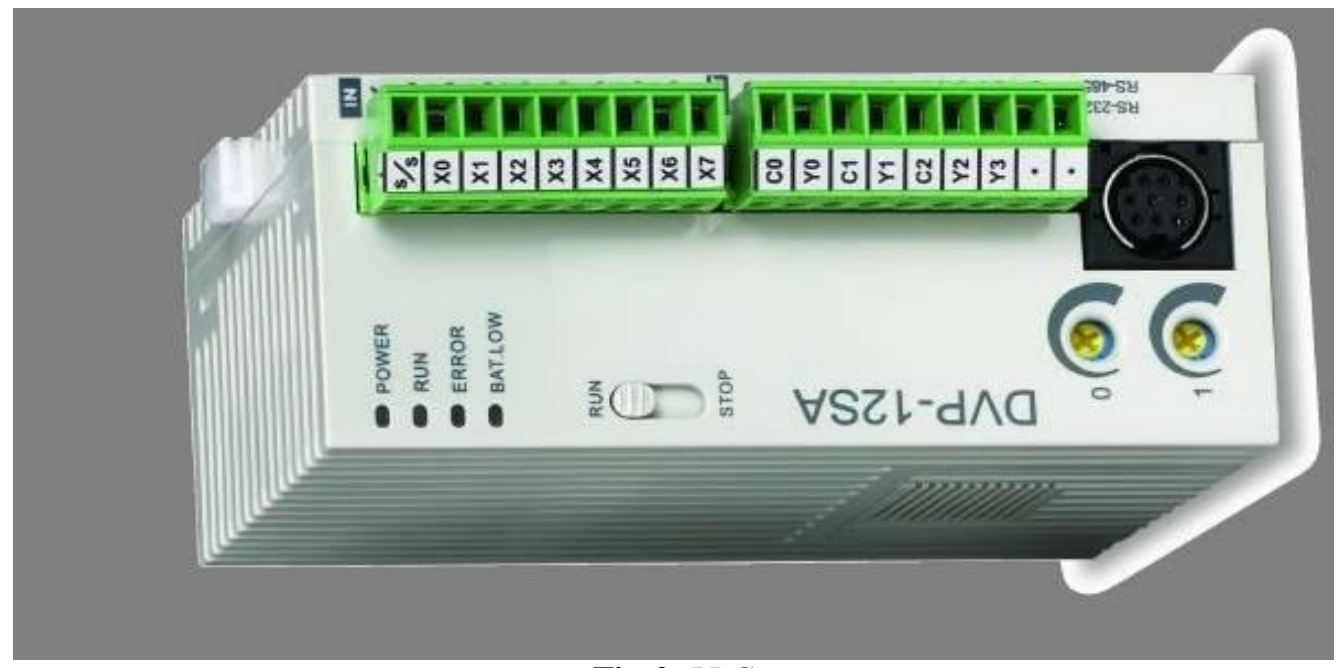

Fig-2: PLC

A Programmable Logic Controller (or PLC) is a specialized digital controller that can control machines and processes. It monitors inputs, makes decisions, and controls outputs.

For PLC communication, ladder programing is required.

PLC is used primarily to replace relays, timers, and counters; it's hard to beat the simplicity and usefulness of ladder diagram programming.

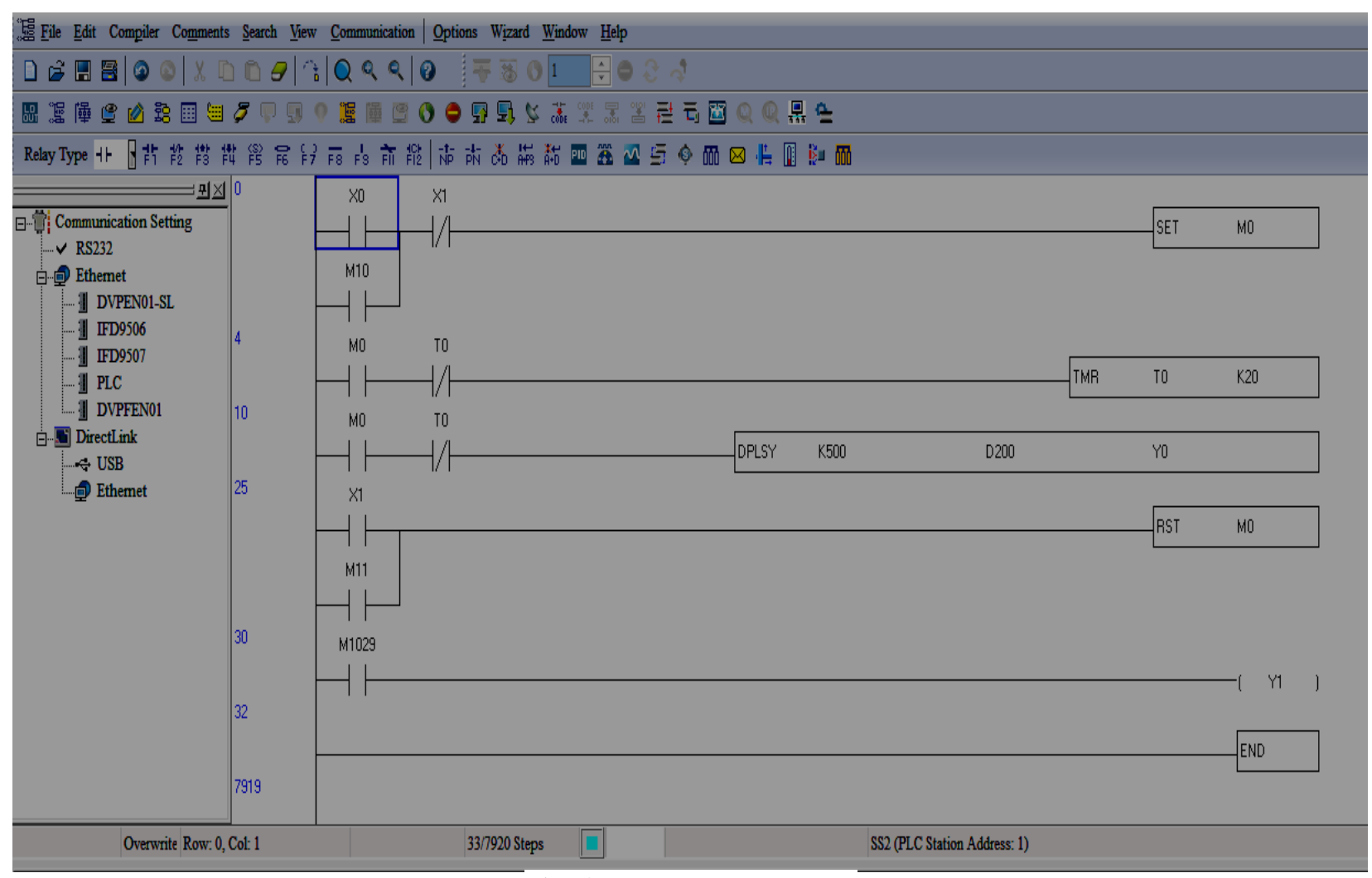

Fig- 3: Ladder programming

The variables used in ladder programming are mentioned below

$\mathrm{X} 0=$ start push button, $\mathrm{X} 1=$ Stop push button

T0 = Timer, M0 = memory bit, M1029 = Stepper motor count, Y0 = Output, D200 = bit for no of steps per revolution. 


\subsection{HMI (User Interface) [5]}

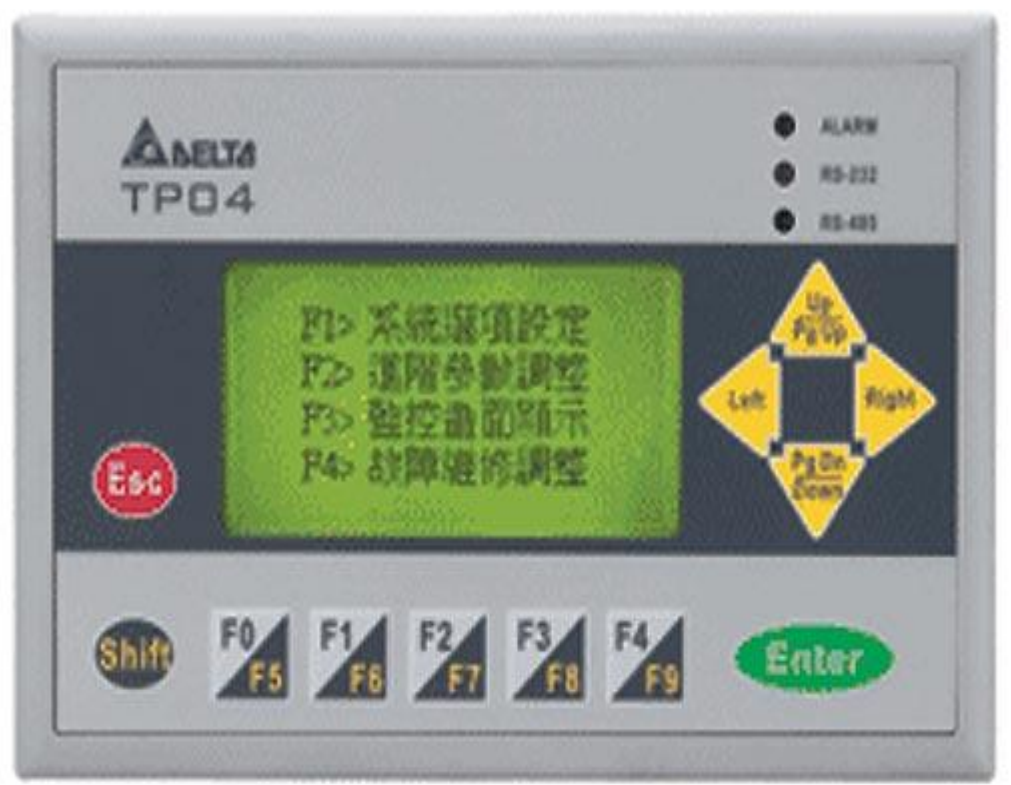

Fig- 4: HMI

PLCs may need to interact with people for the purpose of configuration, alarm reporting or everyday control. A human-machine interface (HMI) is employed for this purpose. Communication cable is used for interaction between PLC and HMI.TP Editor HMI software is used for HMI programming.

As HMI is simple and have limited features unlike computer (have more features), will be very easy for the operator to use.

E.g. we can enter the length to be cut.

Other electrical components used are SMPS, Relays, Stepper motor, and Stepper drive.

\subsection{Rollers}

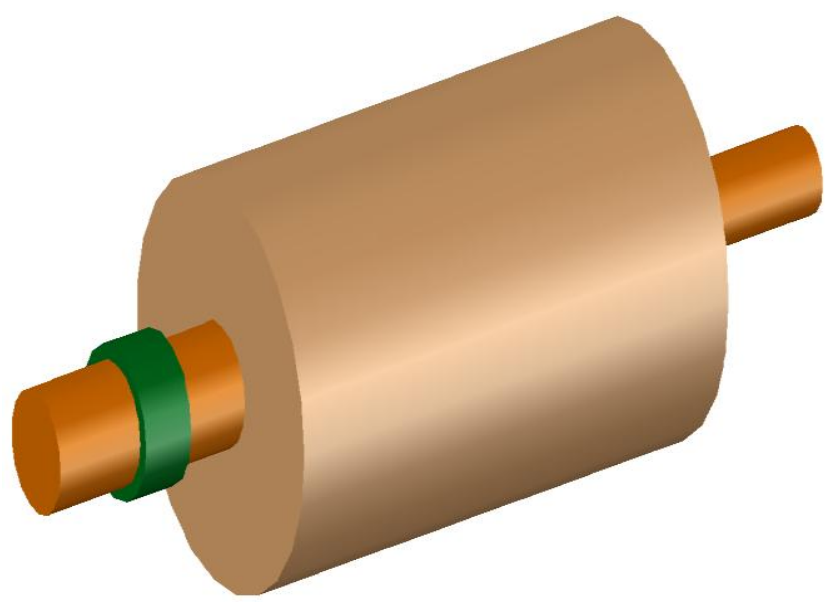

Fig- 5: Roller
As we need a method of holding down the sleeve during the cutting operation. So this function is performed by the rollers. Two rollers upper and lower are been used one will be dummy (upper) and other will be driver (lower) that will be connected to stepper motor through pulley. The upper roller is secured by an adjustable screw (spring loaded) in the side of the roller, to adjust gap between upper and lower roller as per the sleeve diameter. The sleeves will pass through the gap formed in between the two rollers. Also the rotation of the rollers is what gives the sleeves its forward motion allowing for the cutting operation to take place. Rollers are Diamond knurled and high carbon steel metal.

\subsection{Cutting Blade}

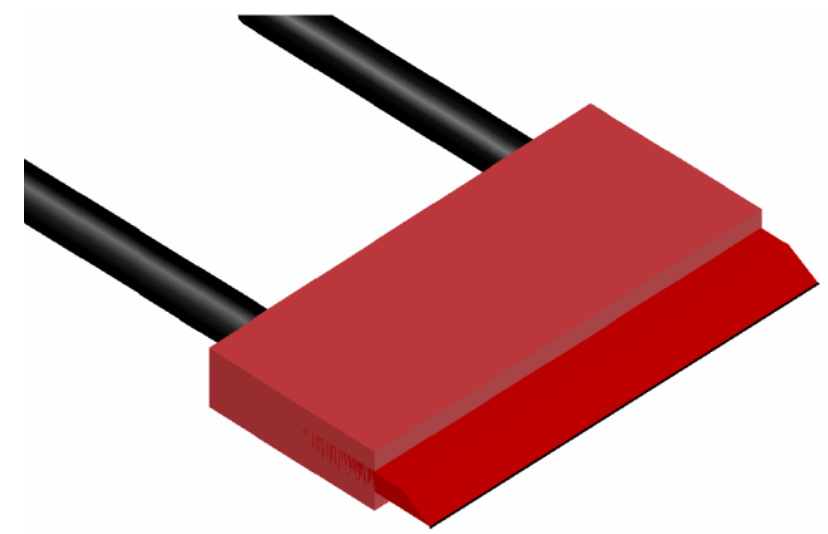

Fig- 6: Cutting blade

The cutting mechanism is a solid blade as shown above. The shearing Blade is made up of high chromium high carbon metal steel. This blade is rectangular block tapered at one edge having dimensions $30 \mathrm{~cm}$ in length, $5 \mathrm{~mm}$ in width, and $5 \mathrm{~cm}$ in height. The blade angle is $60^{\circ}$. 


\subsection{Ball Bearing}

A Machine element that constrains relative motion between moving parts to only the desired motion. Design of the bearing may provide for free linear movement of the moving part or for free rotation around a fixed axis. The relative motion of the pieces causes the round elements to roll with very little rolling resistance and with little sliding

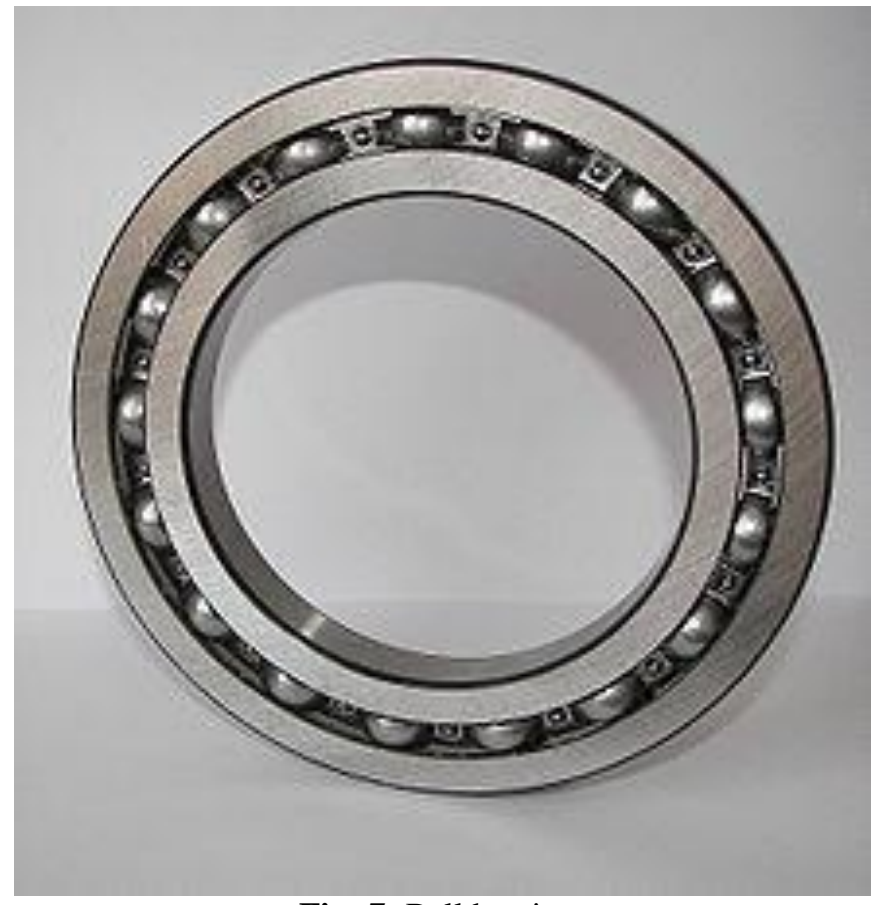

Fig- 7: Ball bearing

\section{WORKING}

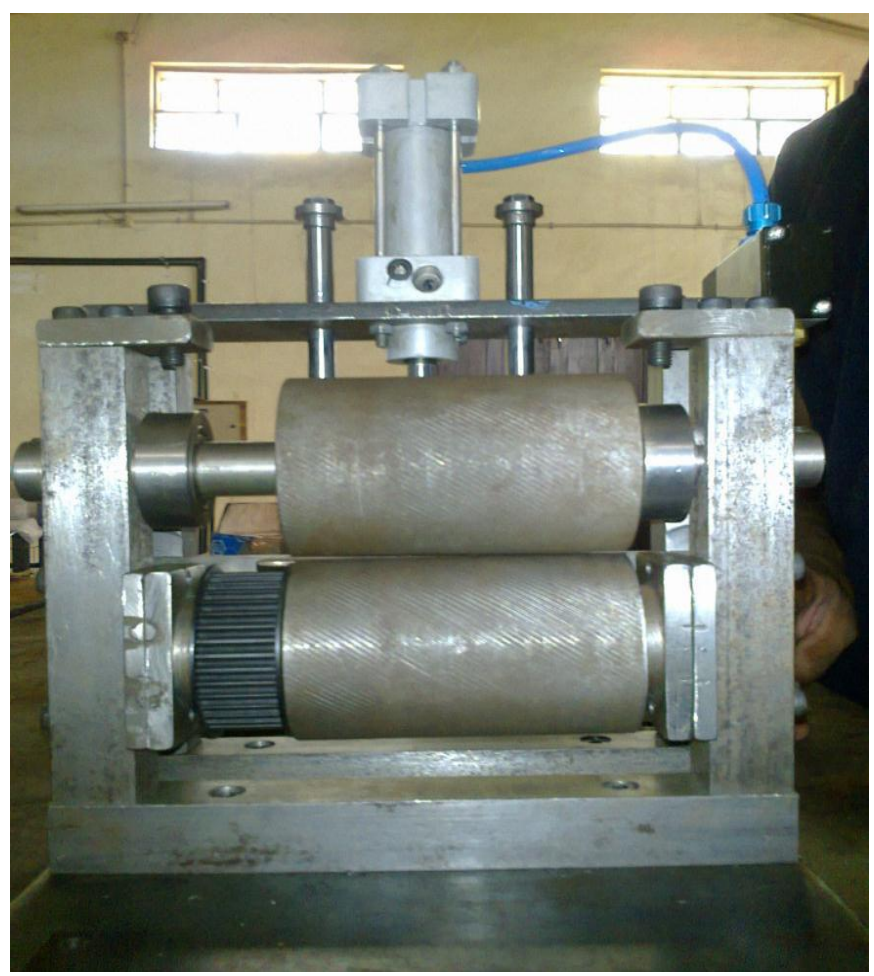

Fig- 8: Shearing machine (front view)
The sleeves will be initially placed on the Guide lanes. First the tip of the sleeves will be passed through the rollers as it will hold the sleeves. Then by giving required cutting length of the sleeve to PLC the Roller will be rotated which will allow the sleeves to pass through the gap between the rollers towards the shearing blade which will shear them off at the end.

The roller is mounted on the shaft with bearing and beside it the pulley is mounted on the shaft. The pulley on the shaft is connected to the steeper motor pulley through the V-belt drive. So any drive given by the motor will result in rotation of the roller. The motor speed reduction and the pulley are adjusted in such a way that we get desired speed/RPM on the roller. In our machine, as per the requirement the pulley ratio should be one to get the steeper motor speed equal to pulley speed.

The cutting action of the blade is done pneumatically. Pneumatic cylinder is bolted and fixed to the frame and placed right above the shearing blade. Cylinder piston is connected to the connector of the shearing blade. As piston moves up-down direction, blade will also move in same direction.

An L-shaped plate fixed to the frame, on which sleeves will be placed in final position to cut after passed in forward direction by rollers. Clearance is given between shearing blade and L-shaped plate. The moving blade will move in up down direction and shear off the sleeves moving forward. The sheared sleeves will slide down and fall into the bin. So the sleeves passing through the machine end up cut and. These cut sleeves are then carried away for their use in insulation.

\section{DESIGN AND CALCULATION}

Design involves the basic components the Roller, the Bearing, the cutting blade and the Frame.

\subsection{Rollers}

Roller is made up of AISI 304 steel standard.

\section{Calculation of roller diameter}

Step angle of stepper motor $($ Hybrid $)=1.8^{\circ}$

Therefore no of steps per revolution $=\frac{360}{1.8}=200 \mathrm{steps} / \mathrm{rev}$.

Since we require $1 \mathrm{~mm}$ for 1 step

$$
\begin{gathered}
200=\pi \times D \\
\mathrm{D}=63.93 \mathrm{~mm} \\
\mathrm{D} \approx 64 \mathrm{~mm}
\end{gathered}
$$

\section{Calculations for finding torque}

$$
\begin{aligned}
& \mathrm{D}=\text { diameter of roller }=6.4 \mathrm{~cm} \\
& \mathrm{~d}=\text { diameter of steel shaft }=2 \mathrm{~cm} \\
& \mathrm{l}=\text { length of shaft }=42 \mathrm{~cm} \\
& \mathrm{~L}=\text { length of roller }=30 \mathrm{~cm} \\
& \rho \mathrm{r}=\text { density of rubber }=1100 \mathrm{~kg} / \mathrm{cm}^{\wedge} 3
\end{aligned}
$$


$\rho s=$ density of plain steel $=7780 \mathrm{~kg} / \mathrm{cm}^{\wedge} 3$

Volume of rubber roller

$$
\mathrm{v}=\frac{\pi}{4} \times\left(D^{2}-d^{2}\right) \times L=456.15 \mathrm{~cm}^{\wedge} 3
$$

Mass of roller

$$
\mathrm{m}_{1}=\rho \times r \times v=0.957 \mathrm{~kg}
$$

$$
\begin{aligned}
\text { Volume of shaft } & =\frac{\pi}{4} \times d^{2} \times l \\
& =131.88 \mathrm{~cm}^{\wedge} 3
\end{aligned}
$$

Mass of shaft, $\mathrm{m}_{2}=\rho \times s \times v$

$$
=1.02 \mathrm{~kg}
$$

Total mass, $\mathrm{m}=\mathrm{m}_{1}+\mathrm{m}_{2}=1.997 \approx 2 \mathrm{~kg}$

$$
\begin{aligned}
\text { Torque }(\mathrm{kg}-\mathrm{cm}) & =m \times \frac{D}{2} \\
& =6.4 \mathrm{~kg}-\mathrm{cm} \\
\text { Force } & =m \times a=2 * 9.81 \\
& =19.62 \\
& \approx 20 \mathrm{~N} .
\end{aligned}
$$

\subsection{Bearing}

$$
\begin{gathered}
v=w \times r^{[2]} \\
0.05=\frac{2 \times \pi \times N}{60 \times 0.034} \\
\mathrm{~N}=14 \mathrm{rpm} \\
\mathrm{R}(\mathrm{a}) \frac{20 \mathrm{~N}}{\downarrow} \mathrm{T}(\mathrm{b})
\end{gathered}
$$

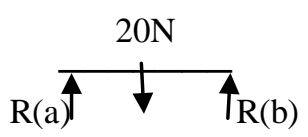

Solving $R(a)=R(b)=P=10 N$

To calculate life of bearing

$$
\begin{aligned}
L 10= & \frac{60 \times N \times L 10 h}{10^{6}} \quad, \text { from data handbook } \\
& =\frac{60 \times 20 \times 8000}{10^{6}} \quad, 20=\text { number of balls } . \\
& =6.72 \text { million rev }
\end{aligned}
$$

Dynamic load capacity $(\mathrm{C})=\mathrm{L}_{10}{ }^{0.33} \times P$

$$
=18.75 \mathrm{~N}
$$

Static load capacity $(\mathrm{C} 0)=\frac{1}{5} \times z \times p$

$$
=20 \mathrm{~N}
$$

From data book, [1]

Table 1: Selection of Bearing

\begin{tabular}{|l|l|l|l|l|l|}
\hline $\begin{array}{l}\text { Principal } \\
\text { dimensions }(\mathrm{mm})\end{array}$ & Basicload rating $(\mathbb{N})$ & Designation \\
\hline d & D & B & C & C & \\
\hline 20 & 32 & 7 & 2700 & 1500 & 61804 \\
\hline
\end{tabular}

\subsection{Cutting Blade}

Cutting block is made out of AISI 304 SS.

Length of the blade $=300 \mathrm{~mm}$,

Width of the blade $=5 \mathrm{~mm}$,

Height of the blade and cutting angle $=50 \mathrm{~mm} \& 60^{\circ}$.

\subsection{Cutting Capacity Of The Machine}

For every rotation of the roller there will be 15 sleeves parallel to each other passing the cutting blade.

As mentioned earlier we require $1 \mathrm{~mm}$ for 1 step of rotation of roller or stepper motor,

Assume required cutting length of sleeve $=1 \mathrm{~mm}$,

So the number of sleeves cut per minute will be $15 *$ no. of steps.

\subsection{Belt Drive}

The belt drive we are using is toothed V-belt drive.

Length of the V-belt $=350 \mathrm{~mm}$

Thickness (width) of the V-belt $=20 \mathrm{~mm}$

Height of the V-belt $=5 \mathrm{~mm}$

\section{DRIVE TRAIN}

The basic components of Drive train are stepper motor, pulley on the shaft and the synchronous belt drive. Belt drive is made out of leather motor is a $108 \mathrm{~W}, 90 \mathrm{rpm}$ motor, $12 \mathrm{~N} / \mathrm{m}$ torque belt drive and the pulleys have a ratio of $1: 1$ to get required rpm on the Roller. Stepper motor is a hybrid type with $1.8^{\circ}$ step angle and 200 steps per revolution. 


\section{FRAME}

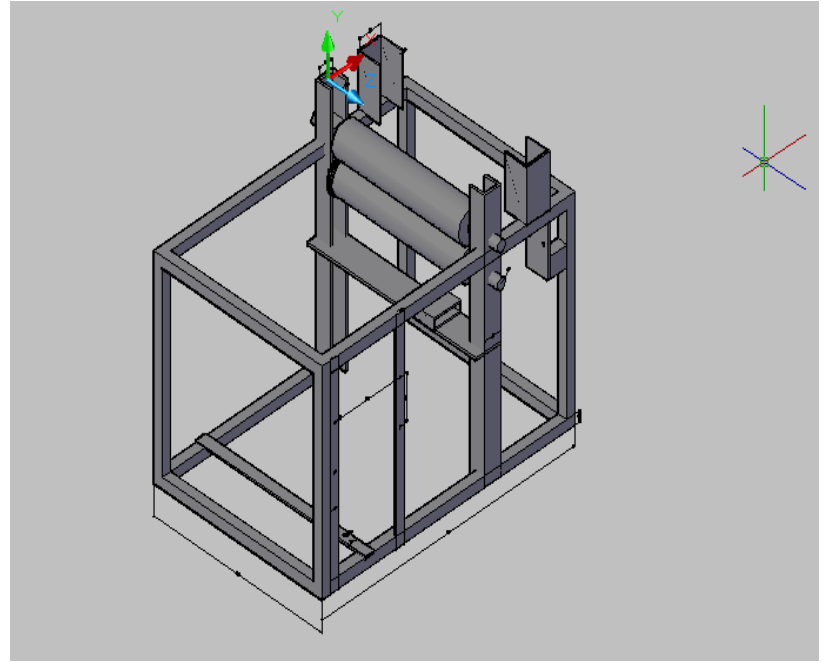

Fig. 9: Frame

Frame is made of stainless steel.

\section{FUTURE SCOPE}

1. Our research can serve as a basis for future machines.

2. Further efficiency calculations can be carried out on machine to maximize production

3. Since it is our own design it can be applied for a patent.

\section{CONCLUSION}

1. As our machine is automated the machine can produce

20- 25 cut pieces per minute.

1. 2. The time required to the $\mathrm{o} / \mathrm{p}$ for machine is less.

2. It is more reliable, Precise, maintenance is less required.

\section{ACKNOWLEDGMENTS}

The authors would like to thank Prof. Neena Panandikar, Associate Professor, Padre conceicao college of engineering , Verna-Goa for her valuable guidance and Mr. Abhay keni (Prop. SHRI SHANTA PUMPS) and SHRI SHANTA PUMPS company for their immense help in fabrication

\section{REFERENCES}

[1]. V. B. Bhandari, "Design of Machine Elements," in Design, 3rd edition Tata McGraw-Hill Education India Pvt.Ltd

[2]. K Madhavan ," Design Data Handbook, " in Design, 3rd editionCBS Publishers and Distributors Pvt Ltd.

[3]. Akshay patil, Automated wire cutting and crimping machine with wire colour detection system using image processing and data sequencing, international journal of advances in science eng. and technology, ISSN23219009 VOL2ISSUE2,April 2014.

[4]. Degarmo, E. Paul; Black, J T.; Kohser, Ronald A. (2003), Materials and Processes in Manufacturing (9th ed.), Wiley, ISBN 0-471-65653-4.
[5]. Bill Hollifield; Dana oliver; Ian nimmo; Eddie habibi, HMI handbook, Unabridged, September 15, 2008 [6]. William Bolton, Programmable logic controllers $\left(4^{\text {th }}\right.$ edition), Newnes 2006.

[7]. en.m.wikibooks.org/wiki/Introductory PLC.

[8]. Fundamentals of programmable logic controllers and Ladder logic (volume 1).

[9]. www.Stepper motor control and stepper drive.co.in. [10]. www.interscience.com/journal/RahulBarathon 